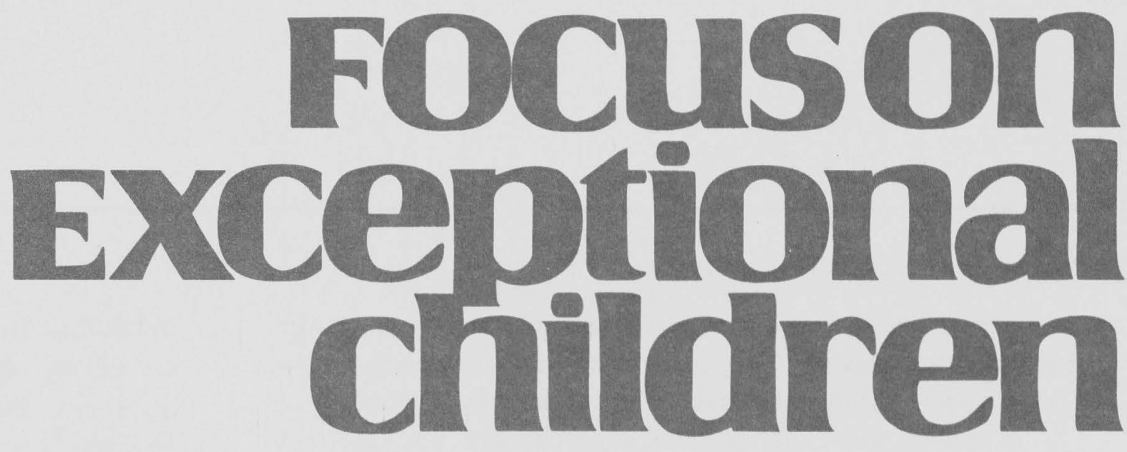

\title{
Searching for Validated Inclusive Practices: A Review of the Literature
}

\section{Joseph B. Fisher, Jean B. Schumaker, and Donald D. Deshler}

Addressing the educational needs of students with mild disabilities appropriately in general education classrooms is a challenge (e.g., Baker \& Zigmond, 1990; Deshler \& Schumaker, 1988; McIntosh, Vaughn, Schumm, Haager, \& Lee, 1993). This is understandable given the institutional demands that today's public school teachers face. Teachers at all grade levels are being assigned to teach larger classes of students, are being required to teach more content while increasing student performance on competency exams, and are not being provided additional planning or instructional time to do so (Joint Committee on Teachers Planning for Students with Disabilities, 1995). The challenge of providing appropriate support to students with disabilities is exacerbated by the reality that many teachers have not been trained to use validated instructional practices with exceptional populations (Deshler \& Schumaker, 1993).

Clearly, placement in mainstream classrooms alone will not guarantee successful outcomes for students with mild disabilities (e.g., Greenwood, Maheady, \& Carta, 1991; Zigmond, Jenkins, Fuchs, Deno, Fuchs, Baker, Jenkins, \& Couthino, 1995). If students with disabilities are to be successful, teachers need information about educational practices that will allow them to meet these students' needs within the context of the institutional demands present in schools today (Kauffman, 1994). More specifically, teachers need information about inclusive practices that are validated, that benefit most, if not all, students in a class, that allow the integrity of the curriculum to be maintained, and that are practical in terms of time and implementation. The purpose of this review is to help meet this need by describing and critically examining the research on existing inclusive practices.

\section{SELECTION OF STUDIES}

The research studies included in this review were identified by searching the Educational Resources Information Center (ERIC) CD-ROM database for the years 1980-1995. In addition, we conducted an ancestral search from the identified articles and solicited inpress and in-preparation from leading researchers in the field. To be selected for the review, a study had to meet the following criteria:

- The study had to be conducted in a general education classroom in which students with learning disabilities, behavior disorders, or mild mental retardation were enrolled. For this review, "general education classrooms" were defined as classrooms with 15 or more students, led by one teacher, in which general education curricula were being implemented.

The authors are all associated with the University of Kansas Center for Research on Learning. 
- The study had to report empirical data on the academic performance of students with mild disabilities. (Though important, studies reporting the social acceptance and social development of students with mild disabilities in general education classrooms were beyond the scope of this review and were not included.)

- The study had to employ an experimental design that controlled for the effects of extraneous variables.

Once selected, the studies were sorted into six categories of inclusive practices: peer tutoring, cooperative learning programs, teaching devices, content enhancement, curriculum revision, and strategies instruction. Each study then was reviewed to identify when possible (a) the number of students participating, (b) the participating students' characteristics, (c) the setting in which the study was conducted, (d) the research design used, (e) the dependent variable(s) being measured, (f) the outcomes for students with mild disabilities, (g) the outcomes for students without disabilities, (h) the amount of instructional time needed, and (i) the levels of teacher and student satisfaction with the practice.

\section{Focuson
exceptional
childiren \\ ISSN $0015-511 \mathrm{X}$}

FOCUS ON EXCEPTIONAL CHILDREN (USPS 203-360) is published monthly except June, July, and August as a service to teachers, special educators, curriculum specialists, administrators, and those concerned with the special education of exceptional children. This publication is annotated and indexed by the ERIC Clearinghouse on Handicapped and Gifted Children for publication in the monthly Current Index to Journals in Education (CIJE) and the quarterly index, Exceptional Children Education Resources (ECER). The full text of Focus on Exceptional Children is also available in the electronic versions of the Education Index. It is also available in microfilm from Xerox University Microfilms, Ann Arbor, MI. Subscription rates: Individual, $\$ 30$ per year; institutions, \$40 per year. Copyright (C) 1995, Love Publishing Company. All rights reserved. Reproduction in whole or part without written permission is prohibited. Printed in the United States of America. Second class postage is paid at Denver, Colorado. POSTMASTER: Send address changes to:

Love Publishing Company

Executive and Editorial Office

1777 South Bellaire Street

Denver, Colorado 80222

Telephone (303) 757-2579

Edward L. Meyen

University of Kansas

University of Kansas Medical Center
Glenn A. Vergason Georgia State University

Kristin Kennedy

Editorial Assistant
Each inclusive practice category and the studies related to it will be described. Moreover, information about the effectiveness of each practice will be summarized with respect to how the practice affected the academic performance of students with and without mild disabilities. Finally, conclusions will be drawn with regard to how well a given practice fits with the realities general education teachers face.

\section{PEER TUTORING}

Peer tutoring is a category of inclusive practice in which one student (the tutor) acts as a teacher, providing instruction to a peer (the tutee). During peer tutoring sessions, the tutor helps the tutee master needed skills by providing instruction, opportunities for practice, clarification, and feedback by following a structured, teacher-developed lesson. Developers of this practice emphasize that, for it to be effective, tutors must be trained how to tutor, teachers must interact with each group to keep students focused, tutee progress must be assessed continually, and tutoring sessions must be scheduled regularly(e.g., Jenkins \& Jenkins, 1985). Several types of peer tutoring have been developed including same-age peer tutoring (Mandoli, Mandoli, \& McLaughlin, 1982) and cross-age peer tutoring (Top \& Osguthorpe, 1987); however, studies describing only two types of peer tutoring have met the criteria established for this review: classwide peer tutoring and classwide peer tutoring with curriculum-based measurement.

\section{Classwide Peer Tutoring}

In the mid-1980s, Delquadri, Greenwood, and their colleagues at Juniper Gardens Children's Project developed a type of peer tutoring called classwide peer tutoring (CWPT) to increase opportunities for active academic responding by disadvantaged and low-achieving students (Delquadri, Greenwood, Whorton, Carta, \& Hall, 1986). In CWPT, a class is divided into two teams that engage in competitions for a oneto two-week period. During a CWPT session, students work in pairs for 15 to 30 minutes. Following a structured, teacherdeveloped lesson, the students tutor one another on the same material, reinforcing correct responses and correcting errors. Each pair accumulates points for its team by responding correctly during the session. At the end of the one- to two-week competition, a test is given over the skills studied. Additional points are awarded to each team for correct test responses. Each team's points are totaled, and the winning team is announced (Pomerantz, Windell, \& Smith, 1994).

Several studies on CWPT have involved students with learning disabilities (e.g., Delquadri et al., 1986; Greenwood,
Stanley F. Love
Publisher 
Delquadri, \& Hall, 1984); however, in only three of these studies have data been reported in which the performance of students with disabilities was separated from the performance of other students. In one of these studies, Delquadri, Greenwood, Stretton, and Hall (1983) examined the effects of CWPT on the weekly spelling test scores of six students with learning disabilities in a third-grade classroom. Teachers implemented CWPT during their normally scheduled spelling period. An ABAB reversal design was used.

Results of the study indicated that during both CWPT conditions, students with and without disabilities made fewer spelling errors on weekly spelling tests. More specifically, in the first CWPT condition, students without disabilities reduced their mean number of errors on 18 spelling words from a baseline mean of 3 to a treatment mean of .5 , and students with learning disabilities decreased their mean number of errors from 9 to 2.5 .

During the subsequent baseline phase, errors for both groups returned to previous baseline levels. When CWPT was reinstated, the spelling errors of students without disabilities dropped to a mean of below 1 , and the errors for students with learning disabilities dropped to a mean of 3 . Moreover, during this phase of the study, all students with learning disabilities earned scores of 80 per cent or higher on each spelling test. The researchers also noted that the teacher and students participating in the study expressed a great deal of enthusiasm for CWPT.

Some researchers have investigated whether the use of CWPT could be extended beyond spelling instruction. Pomerantz, Windell, and Smith (1994), for example, examined the effects of CWPT on the acquisition of science and social studies facts (e.g., What are the strongest storms on earth? [Hurricanes]; Between what months do hurricanes occur? [June through November]). The study was conducted in a fourth-grade classroom with 24 students. Three students with learning disabilities were targeted, and the effect of CWPT on their performance was analyzed using a multiplebaseline-across-settings design. CWPT was implemented first during science instruction and later during social studies instruction. Teachers used CWPT for approximately $12 \mathrm{~min}$ utes a day, at least 3 days each week. Following implementation of the CWPT procedure during science instruction, the three target students' scores on science fact quizzes increased by a mean of 10 percentage points over baseline scores.

The CWPT intervention program then was modified to include additional in-class and resource class supports for the target students (e.g., guided practice with reading the difficult words and phrases on tutoring fact sheets). Following implementation of the modified intervention program for science instruction, target students' scores on science fact quizzes increased an average of 23 percentage points over baseline. Then the modified intervention program was also implemented during social studies instruction. Each target student's recall of social studies facts increased an average of 17.6 percentage points over baseline.

Overall, following the modified intervention during both science and social studies instruction, none of the three students scored lower than $74 \%$ on a science or social studies quiz. The researchers indicated that target students enjoyed CWPT and preferred it to noncompetitive instructional formats, but no formal measures of student satisfaction were reported.

Similarly, Maheady, Sacca, and Harper (1988) conducted a study examining the effect of CWPT on tenth-grade students' recall of social studies content in regular social studies classes, in which class sizes ranged between 15 and 20 students. Fourteen students with mild disabilities and 36 students without disabilities participated. New classroom content was introduced each week during one or two class periods. For the next 2 or 3 days, CWPT was implemented for 20-30 minutes each day. Effects of the intervention were analyzed using a multiple-baseline-across-settings design.

Implementation of CWPT resulted in an immediate and substantial increase in the weekly test scores of students both with and without disabilities. For example, gains for students with mild disabilities averaged 23.15 percentage points, and during the intervention no students with disabilities failed more than one of the 33 administered quizzes. In addition, informal interviews with teachers and students participating in the study indicated a high level of satisfaction with the CWPT procedure.

\section{Classwide Peer Tutoring with Curriculum-Based Measurement}

Variations on the original theme of CWPT have evolved as research on its use has continued. For example, Phillips, Hamlett, Fuchs, and Fuchs (1993) changed CWPT by combining it with curriculum-based measurement (CBM). Unlike CWPT, in which all students work on the same material, students in this "hybrid" method work in pairs on skills matched to their individual abilities. The hope was that through this differentiated instruction, student achievement on basic skills would improve.

Using a control-group design, the researchers measured the effect of the combined method on the basic math skills of elementary students. Data were collected on 120 students, 40 of whom had learning disabilities. For the study, CWPT ses- 
sions were implemented approximately 30 minutes a day, twice a week. Results of the study indicated that students who received the combined method scored significantly higher on math tests than students who received traditional math instruction, regardless of ability (average-achieving, low-achieving, or learning disabled). Despite these results, the authors expressed concern about the achievement of the students with learning disabilities. Of the students with learning disabilities who received CWPT with CBM, only $60 \%$ achieved higher scores than the control students with learning disabilities.

\section{Conclusions}

Overall, results of the studies that focused on effects of CWPT and CWPT with CBM lend support for their use as inclusive practices. In each of the four studies, implementation of CWPT and CWPT with CBM improved the academic performance of students with mild disabilities. Likewise, in the three studies reporting academic performance data for students without disabilities, similar effects were found. Moreover, in three studies (Delquadri et al., 1983; Maheady et al., 1988; Pomerantz et al., 1994) the levels of improvement for students with mild disabilities on classroom tests (e.g., spelling tests, social studies tests) were socially significant. That is, when students with mild disabilities were in the peer tutoring condition, they scored high enough on tests and quizzes to earn passing grades, whereas they were failing previously. In addition, anecdotal reports provided by Delquadri et al. (1983), Maheady et al. (1988), and Pomerantz et al. (1994) suggest that teachers and students alike were satisfied with peer tutoring as an instructional procedure.

Although the results are positive, the conditions under which they were derived must be considered. In each of the studies, students used peer tutoring to learn factual information such as spelling words and social studies, science, and math facts. What remains unknown are the effects of this practice on more complex learning tasks, especially those requiring higher order thinking in the higher grades. In addition, in two of the four studies described, the setting where CWPT took place was unlike that of typical general education classrooms. For example, in the study by Maheady et al. (1988), only 15-20 students were enrolled in each class, and in the study by Pomerantz et al. (1994), students with learning disabilities received additional instruction using CWPT in a resource class to substantially improve their academic gains. Moreover, in one of the two studies in which the classroom setting appeared typical, $40 \%$ of the students with learning disabilities in the peer tutoring condition performed no better than control students with learning disabilities (Phillips et al., 1993).

Finally, whether peer tutoring requires more instructional time than traditional instruction remains unclear. For example, in the Phillips et al. (1993), Maheady et al. (1988), and Pomerantz et al. (1994) studies, peer tutoring was used 12-30 minutes a day, at least twice a week. Whether teachers normally schedule this much class time each week for students to practice math, social studies, or science facts is unknown. In only one of the studies (Delquadri et al., 1983) did the authors provide information about the one-to-one correspondence of normally scheduled instructional time and CWPT time. To build broader support for the use of peer tutoring as an inclusive practice, further studies addressing these issues should be conducted.

\section{COOPERATIVE LEARNING PROGRAMS}

Cooperative learning programs comprise another inclusive practice category. In a cooperative learning program, instructional methods such as direct instruction, small-group instruction, and independent practice are combined with cooperative learning to teach skills and information. Cooperative learning is a term used to describe a range of team-based learning approaches (Damon \& Phelps, 1989). Typically, during cooperative learning activities, students are divided into small "teams" or "achievement groups" of four to five students with varying abilities. While in teams, students are assigned a task, and they work together to complete the task. To do so, the parts of an assigned task often are divided evenly among team members, and team members monitor, assist each other, and provide feedback on one another's work.

Once an assigned task has been completed, a teacher may check what students have learned in several ways. Some teachers choose to give each student on a team a test. Other teachers choose to give each team of students a test to complete cooperatively. Still other teachers choose to have each team of students turn in a group project. Studies describing three types of cooperative learning programs have met the criteria established for this review: Team-Assisted Individualization, Cooperative Integrated Reading and Composition, and Classwide Student Tutoring Teams.

\section{Team-Assisted Individualization}

Team-Assisted Individualization (TAI) is a cooperative learning program involving students in heterogeneous 
groups of four or five students (Slavin, Madden, \& Leavey, 1984a). Each member of a team works on individualized materials at his or her own rate. Team members help one another and take responsibility for management tasks such as checking work. As students work using TAI, the classroom teacher is free to work on new material with small groups of students. At the end of each week, the teacher awards certificates to teams based on the quantity and quality of their work.

Two studies of TAI as an inclusive practice have been conducted. In the first, Slavin, Madden, and Leavey (1984a) examined the effect of TAI on students' math achievement. A total of 504 third-, fourth-, and fifth-grade students, of whom 117 had mild disabilities, participated. These students received either traditional whole-group math instruction or TAI instruction for 12 weeks. A pretest, posttest control-group design was used, and data were analyzed using analysis of covariance, with pretest scores and grade level serving as the covariates. Overall results of the study revealed no significant differences between the posttest math achievement scores of control and experimental groups. Furthermore, no significant differences on the posttest math achievement scores were reported between control and experimental students with disabilities. Questionnaire data indicated that students in the experimental condition had more positive attitudes toward math class than did control group students.

In a follow-up study, Slavin, Madden, and Leavey (1984b) used a similar methodology to examine the effects of TAI on the math achievement of students with and without disabilities. The subjects were 1,371 third-, fourth-, and fifth-grade students. Of these students, 113 were receiving special education services. Students were assigned to either the control or the experimental group and participated in the study for 24 weeks (as contrasted with 12 weeks in the previous study). Again, a pretest, posttest control-group design was used. Results of the study revealed significantly higher posttest scores on both computational and conceptual math achievement for students with and without disabilities receiving TAI instruction than students receiving traditional math instruction. The magnitude of this difference in performance approached half a grade level.

\section{Cooperative Integrated Reading and Composition}

Cooperative Integrated Reading and Composition (CIRC) is a cooperative learning program developed for use during reading, writing, and language arts instruction in elementary classrooms The CIRC program includes three principal activ- ities: basal related activities, direct instruction in reading comprehension, and integrated language arts and writing activities (Slavin, Stevens, \& Madden, 1988). In each of these three activities, students work in heterogeneous cooperative learning teams. For example, during basal reading activities, students work in teams conducting partner reading and spelling, decoding, and vocabulary practice. During integrated language arts and writing activities, students help each other plan, draft, revise, and edit compositions in cooperative teams. Moreover, at home each night, students read with their parents for 20 minutes or longer.

Two studies have been conducted to examine the effects of the CIRC program as an inclusive practice for students with disabilities. In the first, Slavin et al. (1988) implemented the CIRC program with 450 third- and fourth-grade students, 22 of whom had learning disabilities. The CIRC program was implemented for 24 weeks. A pretest, posttest control-group design was used. Following the posttest, researchers analyzed the effects of the CIRC program and traditional instruction on the participating students' reading and writing achievement using analysis of variance.

Overall, CIRC students scored significantly higher on reading comprehension, language expression, and language mechanics than did control students. Regarding the students with learning disabilities, those receiving CIRC scored significantly higher on standardized tests measuring reading comprehension and reading vocabulary than students with learning disabilities in the control groups. More specifically, these students gained 1.92 grade equivalents more than control students in reading comprehension and 1.44 grade equivalents more than control students in reading vocabulary.

In the second study, Jenkins, Jewell, Leicester, Jenkins, and Troutner (1991) integrated CIRC into a schoolwide model for educating students with disabilities in general education classrooms. For one school year, all aspects of the CIRC program except the direct instruction reading comprehension lessons were used in sixth-grade reading and language arts classes. The authors indicated that the home reading component of the program was not strongly emphasized. A pretest, posttest control-group design was used. Fiftythree sixth graders, including 6 students with mild disabilities, participated in the experimental group, and 69 students, three of whom had disabilities, participated in the control group. Results of the study were analyzed using multiple analysis of variance. The analysis indicated no significant differences between the posttest reading scores of control and experimental students with disabilities or between the posttest reading scores of control or experimental students without disabilities. 


\section{Classwide Student Tutoring Teams}

A third type of cooperative learning program, Classwide Student Tutoring Teams (CSTT), developed by Maheady, Sacca, and Harper (1987), is a hybrid practice combining principles of both peer tutoring and cooperative learning. In CSTT, heterogeneous groups of four or five students follow a structured, teacher-developed lesson to learn skills or content. For example, each team might be given a practice sheet and a deck of numbered cards. To begin, one student from the team, called the tutor, selects a numbered card. The number drawn designates a problem to be answered on the practice sheet. The tutor then instructs his or her team members to solve the problem individually. If a team member solves the problem correctly, he or she receives points. If a second team member answers incorrectly, the tutor provides the correct solution and has the second team member rework the problem. Once each member of the team responds correctly, another team member selects a numbered card, and the process begins again.

The effects of this hybrid on the academic performance of students with and without disabilities in secondary math classes of 15 to 20 students were studied by Maheady et al. (1987) using a multiple-baseline-across-settings design. Participants were 28 students with mild disabilities and 63 students without disabilities enrolled in ninth- and tenth-grade math classes. During the study, CSTT was used 30 minutes a day, twice a week, for 7 weeks.

Following implementation, scores on weekly math quizzes averaged 20.53 percentage points higher during the intervention than baseline for ninth-graders and 23 percentage points for tenth graders. On the average, the math quiz scores of the ninth-grade students with mild disabilities increased 19.24 percentage points. Of these 28 students, two had quiz score averages between $60 \%$ and $70 \%$. Of the remaining students with disabilities, all had quiz score averages of $70 \%$ or higher over the course of the study. Similar results were reported for the tenth-grade students.

\section{Conclusion}

The studies examining the effects of the three cooperative learning programs lend some support to their use as inclusive practices. In the studies by Slavin et al. (1984b), Slavin et al. (1988), and Maheady et al. (1987), implementation of a cooperative learning program improved the academic achievement of students both with and without mild disabilities. In addition, in each of these three studies, students with disabilities made socially significant achievement gains (e.g., within 24 weeks of TAI, on average, students improved nearly half a grade level in math achievement).
Two studies on cooperative learning programs reported nonsignificant results, but these results may be attributed to two factors. The first might be time. In the Slavin et al. (1984a) study of the TAI program, in which nonsignificant results were reported, the program was implemented for only 12 weeks. In the follow-up study on the program (Slavin et al., 1984b), when researchers used similar procedures and implemented the program for 24 weeks, students made significant gains.

The second factor might be fidelity. In the Jenkins et al. (1991) study on the CIRC program, reporting no significant gains, the direct instruction in reading comprehension lessons was omitted, and the home reading activities were not emphasized. In the Slavin et al. (1988) study on the CIRC program, in which significant gains in reading comprehension and reading vocabulary were reported for students with disabilities, all aspects of the program were implemented. Thus, the TAI and the CIRC programs might affect students' academic performance significantly if all aspects of each program are implemented for a sustained period. Nevertheless, because the Jenkins et al. (1991) study was conducted across an entire school year and involved cooperative learning, the contribution of the cooperative learning component of the CIRC program is called into question. Component analyses are needed for further illumination.

Though encouraging, the existing studies on cooperative learning as an inclusive practice expose several limitations. First, the teachers' satisfaction with cooperative learning as an inclusive practice is unknown. Data on teacher satisfaction are critical, for if teachers are not satisfied, the likelihood that they will implement all the components of a cooperative learning program for a sustained period of time is low. Second, additional research examining the settings in which cooperative learning can be implemented as an inclusive practice is needed. To date, only one study has examined the use of cooperative learning as an inclusive practice beyond the sixth grade, and for that study (Maheady et al., 1987) only 15 to 20 students were enrolled in each class. Classes this small are uncommon in most public secondary schools. Third, for both the TAI and CIRC programs, separate, specially designed curricula were implemented. Whether schools would adopt these new curricula willingly is unknown. Finally, the amount of time required to implement cooperative learning programs in comparison to other instructional programs is unclear. Only the study reported by Maheady et al. (1987) provided information on this important instructional variable.

Once data on these factors are collected and reported, more decisive decisions can be made about the use of cooperative learning programs as an inclusive practice. 


\section{TEACHING DEVICES}

Teaching devices, a third category of inclusive practices, are instructional tools teachers use during a lesson to, among other things, elaborate on important content, increase student involvement, or make instruction more explicit (Horton, Lovitt, \& Slocum, 1988; Lovitt \& Horton, 1991). By using teaching devices, teachers hope to mediate student understanding, storage, recall, and/or application of content. Many types of teaching devices (e.g., mnemonic devices, manipulatives, and role-play activities) have been developed and described in both the general and the special education literature. Of these, studies describing only two types of teaching devices meet the criteria established for this review: graphic organizers and study guides.

\section{Graphic Organizers}

Graphic organizers are visual displays teachers use to organize information in a manner that makes the information easier to understand and learn. Among the many terms have been used to describe these visual displays of information are "graphic organizers," "tree diagrams," "semantic maps," "flow charts," and "webs." Theoretically, graphic organizers help students learn by consolidating information into a meaningful whole so they see that what is being taught is not a set of unrelated facts, terms, and concepts (Horton, Lovitt, \& Bergerud, 1990). Graphic organizers are flexible instructional tools used to improve students' comprehension of stories, organization of their own written stories, and understanding of difficult concepts.

Horton, Lovitt, and Bergerud (1990) reported a series of three studies conducted to determine the effectiveness of graphic organizers as an inclusive practice. In the first study, the researchers compared the effects of a teacher-directed graphic organizer to the effects of self-study on high school students' ability to depict relationships among pieces of factual information. The study group employed a group design with counterbalanced treatments. Participants were 180 seventh- and tenth-grade students, of whom eight were students with learning disabilities. Students were assigned to one of two experimental groups. Each group was exposed to two treatment conditions, but in the opposite order. In one condition, self-study, students read and took notes on a text passage. In the other condition, teacher-directed graphic organizers, students read a more difficult text passage and completed a blank graphic organizer with the teacher's assistance. Each treatment took 45 minutes. Following each treatment, the groups were quizzed to determine their knowledge of relationships among parts of the text.
The results of the study revealed that students both with and without learning disabilities scored significantly higher on quizzes following the teacher-guided graphic organizer condition than during the self-study condition. The mean quiz scores of students with learning disabilities were $30 \%$ correct after self-study and $73 \%$ correct after teacher-directed graphic organizers. For students without learning disabilities, the average scores were $63 \%$ after the self-study condition and $95 \%$ after the graphic organizer condition.

Using the same subjects and methodology, the researchers conducted a second study that compared the effects of a student-directed graphic organizer to self-study on students' ability to depict relationships among pieces of information. Each condition took 45 minutes. For the student-directed graphic organizer condition, students read a story and filled in a blank graphic organizer independently. Overall, results of the second study were similar to those of the first. When compared to self-study, students with and without disabilities who had created organizers scored significantly higher on quizzes than they did during the self-study condition. In fact, for students with disabilities, the average quiz scores were $19 \%$ after the self-study condition and $71 \%$ after the graphic organizer condition. Likewise, the average quiz scores of students without disabilities were $56 \%$ and $89 \%$ for self-study and graphic organizer conditions, respectively.

In the third study (Horton et al., 1990), a variation on the student-directed graphic organizer was compared to selfstudy. Students were provided a list of facts and ideas and consulted the text to determine which facts and ideas were related. Next, they filled in a blank graphic organizer independently. Again, each condition was implemented for 45 minutes, and a group design with counterbalanced treatments was used. For the study, 229 seventh-and tenth-grade students, four of whom had learning disabilities were assigned to one of the two groups. Each group received both conditions, but in the opposite order. Results of the study indicated that the students received significantly higher quiz scores when they completed the graphic organizers compared to when they did self-study. Specifically, students with learning disabilities completed $67 \%$ of the quiz items correctly after creating graphic organizers compared to $10 \%$ when using self-study.

\section{Study Guides}

Another teaching device teachers use to promote student learning of important content in inclusive classes is the study guide. Like graphic organizers, study guides are flexible tools that teachers use to support student understanding of textbook 
passages, which often are organized poorly and difficult to comprehend (Lovitt \& Horton, 1988). Study guides have been designed with varying formats and can be used at varying points during a lesson. For example, a study guide may take the form of a teacher-prepared outline, given prior to reading a chapter, listing the important main ideas from that chapter, or it may consist of a list of questions, given following instruction, highlighting the important main concepts and vocabulary terms in a unit of study. Four studies have been conducted to measure the effectiveness of study guides as an inclusive practice.

In two separate studies reported together, Horton and Lovitt (1989) examined the effects of study guides. In the first study, the effects of a teacher-directed study guide were compared to the effects of self-study on students' recall of main ideas from text. The teacher-directed study guide consisted of 15 short-answer questions on main ideas taken from the beginning, middle, and end of a textbook passage. When guiding students to use the study guide, the teacher: (a) instructed students to read and reread an assigned section of text, (b) led students to complete their study guide as the class answered the questions as a group, (c) told students to study their completed study guide, and (d) gave students a 15-item multiple-choice quiz over the reading section. The study was conducted in both middle- and high-school science and social studies classes. For the study, 121 high-school students, 8 of whom had learning disabilities, were assigned to one of the two groups. A group design with counterbalanced treatments was used. Each group received both the study guide and selfstudy conditions, but in the opposite order.

Results of the study revealed that following the teacher-directed study-guide condition, students recalled significantly more main ideas from the text than during the self-study condition. The average test scores of students with learning disabilities were $49 \%$ correct during the self-study condition, compared to $68 \%$ correct during the study-guide treatment. Students without disabilities earned average scores of $80 \%$ and $93 \%$, respectively, as a result of the two conditions.

In their second study, using the same sample and research methodology, Horton and Lovitt compared the effects of a student-directed study-guide condition to a self-study condition on students' recall of main ideas from text. In the student-directed study-guide treatment, students guided their own completion of the study guide independently. The results were similar to those of the first study, indicating that when the student-directed study guides were completed, students recalled significantly more main ideas from text then they did during the self-study condition. Specifically, the test scores of students with learning disabilities earned average scores of
$43 \%$ during the self-study condition and $77 \%$ during the study-guide condition. By comparison, students without learning disabilities earned average scores of $55 \%$ and $87 \%$, respectively, as a result of the two conditions.

In a similar study, Horton, Lovitt, Givens, and Nelson (1989) again implemented the use of study guides consisting of 15 short-answer main-idea questions. In this study, however, use of the study guide was guided by a computer program. Via a computer, students were presented a passage of text to read, then were given a 15 -item study guide to complete, and finally were presented with a multiple-choice test. Implementation of the computerized study guide intervention took 40 minutes of instructional time. Thirty-one ninth-grade students enrolled in a low-track secondary general education world geography class participated in the study. Of these students, 13 had learning disabilities.

When the quiz scores students earned during the computerguided instruction condition were compared with those earned during a self-study condition, students with learning disabilities and without disabilities both scored significantly higher after completing the study guide than they did after self-study. The students with learning disabilities earned average scores of $42 \%$ correct during the self-study condition, compared to $76 \%$ correct during the study-guide treatment. Students without disabilities earned average scores of $58 \%$ and $77 \%$, respectively, after the two treatments. In follow-up interviews with the students, $86 \%$ indicated that they preferred learning information through computers rather than from a textbook.

Finally, Higgins and Boone (1992) measured the effects of computer-based study guides on students' recall and understanding of textbook content. The study guide was composed of computer-based text and graphics linked through a series of "buttons." While reading the computerized text, students could highlight a "button" on the screen, which then would access additional information to clarify, enhance, or supplement their understanding. In addition, multiple-choice questions, interspersed within the text, were presented. To move ahead in the text, students first had to answer these questions correctly. This format allowed students to proceed nonsequentially through a text to retrieve information and to answer questions on important text material. Forty ninthgrade students enrolled in a history class participated in the study. Of these students, 10 had learning disabilities. Students were assigned to one of three conditions: lecture only, lecture with a computerized study guide, and computerized study guide only. Each condition was used during 30 minutes of instruction over 10 days.

Over the course of the study, each group of students completed a pretest, 10 multiple-choice quizzes, a posttest, and a 
retention test. Each set of scores was analyzed using analysis of variance. Overall, positive effects favoring use of the computerized study guide were apparent; unlike the results of previous studies on study guides, however, the effects were not statistically significant.

\section{Conclusion}

Six of seven studies that measured the effects of teaching devices lend support for their use as an inclusive practice. In all but the Higgins and Boone (1992) study, students with and without disabilities made significant gains in academic performance. In addition, the improvements in student performance were socially significant (i.e., moved failing students into the passing range). Use of the teaching devices also seemed to allow teachers to maintain the integrity of their content. In the studies, teachers used both the graphic organizers and study guides to support, not supplant, the curricula for their courses. Moreover, the teaching devices were shown to be effective at varying secondary grade levels (e.g., seventh-, ninth-, and tenth-grades) in varying content-area classes (e.g., science, social studies, geography) and under varying instructional arrangements (e.g., teacher-mediated instruction, student-mediated instruction).

Still, these interventions may have limitations. Specifically, the feasibility of using graphic organizers and study guides must be considered. In each of the studies described, teachers did not make the teaching devices they used; rather, they were constructed by the researchers. In both the Horton et al. (1989) and Horton et al. (1990) studies, the authors reported that results of follow-up research indicated that teachers can prepare a graphic organizer or a study guide for use in their classrooms in approximately 50-60 minutes. Whether teachers actually will prepare and use the devices across a school year has not been determined. No information is available on the time required to create computerbased study guides.

In addition, consumer satisfaction data on the use of the teaching devices is limited. In each of the described studies, no teacher satisfaction data are reported. Moreover, the only data reported on student satisfaction (Horton et al., 1989) pertain to the students' satisfaction using computers, not their satisfaction with study guides. Overall, graphic organizers and study guides seem to be promising means for improving the achievement of students with and without disabilities in a variety of general education classes. What is unclear is whether preparation of study guides and graphic organizers requires too much time by teachers to be acceptable and whether teachers and students are satisfied with their use.

\section{CONTENT ENHANCEMENT ROUTINES}

Content enhancement routines are inclusive teaching practices that combine an interactive instructional sequence with a teaching device. They are designed to involve students during the learning process and to prompt teachers' explicit use of the teaching device. Specifically, content enhancement routines help teachers carefully organize and deliver content information and help students identify, organize, comprehend, and recall critical content information (Lenz, Bulgren, \& Hudson, 1990; Schumaker, Deshler, \& McKnight, 1991). In recent years, six studies on content enhancement routines have been conducted by researchers associated with the University of Kansas Center for Research on Learning (the parent organization for the Institute for Research in Learning Disabilities). These studies examined the effectiveness of three types of routines: organizational routines, understanding routines, and a recall routine.

\section{Organizational Routines}

Organizational routines were designed to help students understand how presented content fits together into a "big picture." Specifically, teachers use these routines in advance of a lesson or unit of study to depict for students a method for organizing the content, to define the relationships among pieces of the content, to clarify what content has been presented in relation to what content is left to be taught, and to help students self-monitor what content they have learned. Overall, these routines are used to create frameworks for understanding the structure of presented content. The frameworks orient students to where they have been, where they are, and where they are going in a learning situation (Fisher, Knight, \& Lenz, 1996).

For example, before teaching a lesson on the water cycle, a teacher may tell her students that they are going to study the water cycle to orient them to the topic, may ask her students questions about the water cycle to assess their background knowledge, may present a graphic organizer depicting the specific content to be learned, and may define new terms (e.g., evaporation, precipitation) to clarify students' understanding.

Two studies examining the effects of organizational routines on the academic performance of students with mild disabilities in general education classrooms have been conducted. In the first, Lenz, Alley, and Schumaker (1987) measured the effects of an organizational routine, called the Lesson Organizer Routine (Lenz, Marrs, Schumaker, \& Deshler, 1993), on student recall of content presented in a lesson. Teachers used this routine at the beginning of lessons to 
enhance their delivery of content. Seven general education teachers and seven students with learning disabilities (one from each teacher's class roster) participated in the study. Following a baseline period in which the seven students' recall of the presented content was measured, each teacher received training in and began using the routine.

Although the teachers implemented the routine in accordance with their training, the students' recall performance scores did not improve initially. In response to this outcome, the researchers taught each student, for one hour, how to identify and record information overviewed during teacher use of the Lesson Organizer Routine. Following this individualized instruction, scores on the recall measures improved substantially for the students with learning disabilities. For example, during baseline, the average number of statements about information in the lesson recalled by Students 1, 2, 3, and 4 was 13.7, and for Students 5, 6, and 7 was 22. Following the intervention, the average number of statements rose for Students 1, 2, 3, and 4 to 29, and for Students 5,6 and 7 to 33.67 .

In a second study (Lenz, Schumaker, Deshler, et al., 1993), use of the Lesson Organizer Routine was expanded for introducing and guiding student learning during the course of a unit. This new routine, called the Unit Organizer Routine (Lenz, Bulgren, Schumaker, Deshler, \& Boudah, 1994) was used by six secondary science and social studies teachers in their classes. To evaluate the effects of teacher use of the routine on the academic performance of students with and without disabilities, a multiple-baseline design was employed. Six secondary social studies and science teachers implemented the routine with their classes across a school year to enhance delivery of content.

As in the previous study, results of the unit organizer study indicated that the performance of students with and without learning disabilities improved substantially over baseline, as reflected in unit test scores. For example, the unit test scores of students with learning disabilities increased an average of 10 percentage points over baseline. Moreover, following implementation of the routine, seven of the eight participating students with learning disabilities earned average scores of $72 \%$ or higher on unit tests.

At the conclusion of both studies, the participating teachers completed exit questionnaires regarding the organizational routines. All teachers indicated that they intended to continue using the routines in their classes in which students with learning disabilities were enrolled. Many of the teachers also noted that they found the organizers useful and were satisfied with the effect on the performance of students with disabilities.

\section{Understanding Routines}

To help students understand important, abstract and/or complex concepts presented during a lesson, teachers can use a second type of content enhancement routine, called understanding routines. Understanding routines guide teachers' translation of concepts into easy-to-understand formats, primarily by combining new information with students' prior knowledge. Specifically, understanding routines help students comprehend and acquire new information by specifying what concept is going to be learned, accessing the knowledge students possess related to the new concept, explicitly depicting information related to the new concept in a graphic organizer, connecting student knowledge with the new concept, and summarizing what has been learned in a brief written statement.

Overall, understanding routines help teachers help students integrate and store new knowledge with old knowledge. For example, in social studies, a teacher might use an understanding routine to teach students the concept of democracy by brainstorming what students already know about democracy, outlining the characteristics always, sometimes, and never present in a democracy, providing examples and nonexamples of democracy, and summarizing democracy in a definition.

In a series of studies, Bulgren and her colleagues examined the effects of three different understanding routines on students' abilities to understand concepts. In the first study, Bulgren, Schumaker, and Deshler (1988) evaluated the effects of the Concept Mastery Routine (Bulgren, Deshler, \& Schumaker, 1993) on the test scores of 64 high school students, 32 of whom had learning disabilities. The Concept Mastery Routine was designed to help teachers present, practice, and review new concepts through the use of a graphic organizer. Teachers participating in the study required from 13 to 45 minutes to present a concept to students using the routine. They used the routine across a school semester. The students scored significantly higher on both publisher-made classroom tests and researcher-constructed concept acquisition tests when the routine was used versus when it was not used. On regularly scheduled classroom tests, the scores of students without learning disabilities improved from a mean of $72 \%$ correct at baseline to $87 \%$ correct following use of the routine, whereas the mean scores of student with disabilities improved from $60 \%$ to $71 \%$ correct. Similarly, on tests measuring student acquisition of concepts, the scores of students without learning disabilities improved from a mean of $49 \%$ correct at baseline to $83 \%$ correct following use of the intervention, whereas the scores of students with disabilities improved from $40 \%$ to $62 \%$ correct. Unfortunately, after implementing the routine, one-fourth of the students with learning disabilities were not scoring at or above the $60 \%$ level on the 
classroom tests, and one third continued to score below $60 \%$ on the concept acquisition tests.

In two additional studies, Bulgren and her colleagues studied the effects of two additional routines on students' understanding of concepts. The routines are the Concept Anchoring Routine (Bulgren, Schumaker, \& Deshler, 1994a) and the Concept Comparison Routine (Bulgren, Lenz, Deshler, \& Schumaker, 1995). The concept anchoring routine was designed to clarify students' understanding of a new concept by relating the new concept graphically to a similar concept that students already understand. For example, students might be introduced to the functions of the parts of the eye by relating them to the functions of the parts of the camera. The concept comparison routine was designed to enrich students' understanding of two or more concepts by exploring and graphically organizing their similarities and differences. For example, the Concept Comparison Routine might be used to compare and contrast the characteristics of democracy and communism.

In both studies, the routines were used with secondary students with high, average, and low achievement and learning disabilities, in general education science classes. In the Concept Anchoring Routine study (Bulgren, Schumaker, Deshler, 1994b), eight intact, secondary science classes participated. A total of 83 students, 28 of whom had learning disabilities, were enrolled in the classes. The classes were assigned randomly to one of two groups. Both groups received instruction from a researcher (a certified teacher) on two concepts for 50 minutes during regularly scheduled classes. For the first group, the Concept Anchoring Routine was associated with the first concept and traditional instruction was associated with the second concept. For the second group, traditional instruction was associated with the first concept and the Concept Anchoring Routine was associated with the second concept. Through the use of a posttest, the researchers analyzed the effects of the routine versus traditional instruction on the students' knowledge of the two concepts.

Results showed that all students answered significantly more questions correctly about the concept that had been associated with the routine than about the concept that had been associated with traditional instruction. More specifically, students with learning disabilities correctly answered an average of $36 \%$ of the questions on the concept paired with traditional instruction and $63 \%$ of the questions on the concept paired with the routine. Average-achieving students correctly answered $69 \%$ of the questions on the concept paired with traditional instruction and $88 \%$ of the questions on the concept paired with the routine.

In the Concept Comparison study (Bulgren, Lenz, Schumaker, \& Deshler, 1995), six intact secondary science classes participated. A total of 107 students, including 37 students with learning disabilities, were involved. Classes were assigned randomly to an experimental or a comparison group. The experimental classes were presented a lesson by a researcher (a certified teacher) comparing and contrasting two concepts using the Concept Comparison Routine. The comparison classes were presented the same information using traditional instruction. Results of the posttest showed that students in the experimental classes correctly answered significantly more questions about the two concepts than did students in the comparison classes. For example, students with learning disabilities in the comparison classes earned average scores of $57 \%$ and in the experimental classes earned average scores of $71 \%$ on the posttest. Low-achieving students in the comparison classes earned average scores of $63 \%$ and in the experimental classes earned average scores of $86 \%$.

Bulgren and her colleagues also conducted two studies (Bulgren, Schumaker, \& Deshler, 1995; Bulgren, Deshler, \& Schumaker, 1995) to determine whether teachers could learn to implement the concept anchoring and Concept Comparison Routines. Results of the multiple baseline designs indicated for each routine, that teachers implemented on average $92 \%$ of the instructional procedures after two hours of training. Moreover, the teachers continued to use the routine across a school semester and maintained this performance level.

At the end of each of these studies, participants were asked to complete satisfaction questionnaires. Students ratings were in the slightly satisfied to satisfied range for all three understanding routines. The teachers in the studies using a routine across a semester indicated they were satisfied with the routines, found them easy to use, and would recommend them to other teachers.

\section{A Recall Routine}

In addition to organizational and understanding routines, a third type of content enhancement routine has been developed to help students recall critical content information. This routine, called the Recall Enhancement Routine (Bulgren, Schumaker, \& Deshler, 1994c), was designed to enhance the concreteness and meaningfulness of information presented during a lesson or unit of study, thereby making the information easier to recall. A central component of this interactive routine is the use of mnemonic devices. When using the routine, teachers follow a series of steps to cue students about the importance of certain content, to show or co-construct with students a mnemonic device for remembering the important content, and to review the content and the mnemonic device. 
For example, when presenting information from a lesson on newspaper editors' code of ethics, a teacher using the recall enhancement routine would provide his or her students the information and help them decide if it is important and if it should be remembered. If the teacher and students agree the information is important and should be remembered, the teacher might explain that the first letter from each of the four parts of the code (i.e., be Fair, Accurate, Impartial, and Responsible) can be isolated to form the acronym FAIR. In addition, the teacher might tell his or her students that they can construct the sentence, "Newspaper editors are obliged to be FAIR," to help them remember the code. Alternatively, the teacher might coconstruct appropriate mnemonic devices with the entire class.

The recall enhancement routine as an inclusive practice was examined in one study in which, Bulgren et al. (1994c) measured the effectiveness of the routine on retention and recall of information of students with and without learning disabilities. Forty-one seventh- and eighth-grade students, including 18 with learning disabilities, were assigned randomly to experimental and control classes. Both classes received a 45-minute lecture taught by a researcher (a certified teacher) on the same social studies content. The content of the lecture was divided into two sets. At the end of the lecture, the control group reviewed both sets of content using repetitious review. The experimental group reviewed the first set of content using repetitious review, and the second set of content using the recall enhancement routine.

Posttest scores of the two groups related to the content set that had been reviewed repetitiously were not significantly different. Posttest scores of the experimental students on the content that had been paired with the routine were significantly higher than the posttest scores of the control students on this same set of content. For example, control students with learning disabilities earned an average posttest score of $41.80 \%$, whereas experimental students with learning disabilities earned an average posttest score of $70.90 \%$. Control students without disabilities earned an average posttest score of $64.29 \%$, whereas experimental students without disabilities earned an average posttest score of $84.85 \%$. Moreover, $77 \%$ of the experimental students with learning disabilities earned passing scores on the second set of content, compared to only $11 \%$ of the control students with learning disabilities.

\section{Conclusion}

Combined, these studies support the use of content enhancement routines as inclusive practices. In each of the studies described here, use of the content enhancement routines improved the achievement of students with disabilities. In most of the studies, the application of a routine significantly improved the performance of students without disabilities as well. (In the Lenz et al. (1987) study, data were not reported on this variable.) Another factor supporting content enhancement routines as an inclusive practice is that their use did not seem to require teachers to reduce the integrity of the curricula they are required to teach. Finally, in each of the studies reporting satisfaction data, teachers and students alike rated the content enhancement routines positively. In fact, teachers reported finding the routines easy to use and noted they would continue using the routines in their classes.

Still, the content enhancement routines do have limitations. First, some students with learning disabilities did not score in the passing range during the experimental condition. For example, in the study on the recall enhancement routine (Bulgren et al., 1994c), 23\% of the students with learning disabilities in the experimental group did not score above $60 \%$ on the questions related to content paired with the routine. Similarly, in the study on the content mastery routine (Bulgren et al., 1988), one-fourth of the students with learning disabilities did not earn scores above $60 \%$ on the classroom tests, and one-third did not earn passing scores on the concept acquisition tests.

Second, as exemplified in the study by Lenz et al. (1987), before some students with learning disabilities can benefit from a content enhancement routine, they may need to be shown how the routine is designed to help them. Whether general education teachers have time available to provide this additional instruction is unclear. This instruction may have to take place in another setting such as a resource class.

Finally, whether the amount of time required to prepare to use a content enhancement routine limits teachers' development and use of routines is unclear. Bulgren et al. (1988) reported that in the school year following the one in which the study on the Concept Mastery Routine took place, only three of the eight participating teachers reported they had created new concept diagrams to enhance their content instruction even though seven of the teachers reported continuing to use the ones they had designed during the study.

Overall, the content enhancement routines seem to fit many of the realities of general education classes and can improve the achievement of the majority of students with learning disabilities enrolled in general education content classes. Alone, however, they may not be sufficiently powerful to help all of these students earn passing grades.

\section{CURRICULUM REVISION}

One developing category of inclusive practice that has received increasing attention as part of the school reform move- 
ment, based on the proposition that curricula can be designed to enhance student acquisition of information (Engelmann \& Carnine, 1982; Kelly, Gersten, \& Carnine, 1990), involves curriculum revision. Several researchers have conceptualized new curriculum models in content- and skill-area subjects to improve the higher-order thinking of students both with and without disabilities (see Carnine, 1991; Cawley, 1994). Two studies describing one such curriculum model, the BIG Accommodations Program (Carnine, 1994), meet the criteria established for this review.

\section{BIG Accommodations Program}

Carnine and his colleagues at the University of Oregon Center to Improve the Tools of Educators are developing a curriculum designed to enhance students' higher-order thinking (e.g., Carnine, Crawford, Harniss, Hollenbeck, 1995; Carnine $\&$ Kameenui, 1992). This curriculum, called the BIG Accommodations Program, focuses on teaching students generative principles and concepts that underlie subject-area content. For example, to deepen students' understanding of the concept of leadership, the characteristics of leadership exemplified by people such as Jefferson, Washington, and Lincoln may be examined. To broaden students' understanding of the concept, a great leader but a losing general, Robert E. Lee, could be studied to show that the success or failure of a leader depends on more than mere leadership; motivation, capability, and resources are important factors as well (Carnine, 1994). These principles and concepts are presented to students through carefully developed textbook and videodisc units of study.

Though no data are yet available on the effects of the textbook units as an inclusive practice, several studies on use of the videodisc units have been completed. Videodisc units of information contain full-motion video, sound, text, and still images that can be shown on a television monitor. In this way, they are similar to videotapes. A videodisc, however, can store significantly more content than a videotape, and when run in a videodisc player, the information on a videodisc can be accessed randomly. Using a remote-control device, any information on the videodisc can be accessed instantaneously. Moreover, while operating a videodisc from a distance with a remote-control device, a teacher can deliver content on the videodisc to a class of students and circulate to monitor their work and provide feedback.

In one study; Hofmeister, Engelmann, and Carnine (1989) measured the effect of a videodisc chemistry unit on students' understanding of several targeted concepts such as bonding, equilibrium, and organic compounds. Twenty-four highschool students participated in the study. Of these students, nine students without disabilities were enrolled in an advanced placement chemistry class and comprised the comparison group. The experimental group included five learning disabled and 10 low-achieving high school students enrolled in a remedial science course. To begin the study, a pretest was administered measuring the experimental students' knowledge of the targeted chemistry concepts to be taught. Next, the videodisc chemistry program, mediated by the classroom teacher, was implemented. Then the students were posttested. The students in the advanced placement chemistry class were given the same posttest. Whether the students in the advanced placement class received traditional instruction on the targeted concepts prior to the posttest is unclear.

Results of the study indicated that low-achieving students and students with learning disabilities both earned an average score of $17 \%$ on the pretest, whereas on the posttest these same groups of students earned average scores of $82 \%$ and $63 \%$, respectively. The advanced placement chemistry students in the comparison group earned an average score of $71 \%$ on the same posttest. At the end of the study, the remedial and learning disabled students were interviewed to determine their attitudinal reactions to the videodisc program. The students indicated that they preferred videodisc instruction to more traditional forms.

In a later study, Kelly, Gersten, and Carnine (1990) compared the effects of a videodisc math unit to a traditional basal math unit on students' scores on a fractions test. Thirtyfour ninth-, tenth-, and eleventh-grade low-achieving students participated, 17 of whom had learning disabilities. A pretest, posttest comparison-group design was used, and data were analyzed using t-tests. Overall, the results indicated that students in both programs improved their knowledge of fractions significantly. For example, the students in the basal condition improved from a pretest mean below $50 \%$ to a posttest mean of $82.29 \%$. Likewise, students in the videodisc condition improved from a pretest mean of below $50 \%$ to a posttest mean of $96.53 \%$. Overall, the videodisc condition was shown to be significantly more effective than the basal program. Moreover, the videodisc approach was shown to be as effective for the students with learning disabilities as for the lowachieving students in the sample.

\section{Conclusions}

Curriculum revision is a developing area. As a result, the number of studies examining the effects of revised curricula on the achievement of students with disabilities in general education classes is limited. Still, the available data are encouraging, suggesting that a curriculum revision approach 
such as the BIG Accommodations Program may be a viable inclusive practice. In the two studies described above, students with disabilities and low-achieving students without disabilities both improved their knowledge of complex chemistry and math concepts when instructed using the BIG Accommodations Program.

Because available data on revised curricula are limited, more research is needed so teachers can make informed decisions regarding their use. These studies, in addition to describing the effects of revised curricula on student achievement, should examine the amount of class time required for instruction. In the present studies, data on this critical factor are not available. For example, the study by Kelly et al. (1990) does not indicate how many class periods were involved in the experimental teaching and whether that number differed between the experimental and control groups.

Studies examining additional settings in which use of a revised curricula positively affects the achievement of students with and without disabilities are needed as well. Currently, studies support only the use of the revised curricula in "lowtrack" general education classes at the secondary level, thus limiting the settings into which their use can be generalized with confidence.

Finally, only the study by Hofmeister et al. (1989) measured satisfaction with the revised curriculum, and these data were solicited only from students, not teachers. Because revised curriculum programs may alter the teacher's role during instruction, data on both teacher and student satisfaction are needed. Once additional data such as these are available, teachers will be able to make more informed decisions regarding the use of revised curricula in their classrooms.

\section{STRATEGIES INSTRUCTION}

Strategies instruction refers to the process of helping students become self-regulated learners, individuals who have knowledge of how to learn as well as knowledge of how to use effectively what they have learned (Deshler \& Lenz, 1989; Palincsar, David, Winn, \& Stevens, 1991). In the past decade, a large number of studies have examined how to deliver strategy instruction to students effectively (Pressley et al., 1990). Not until recently, however, have studies been conducted examining the application of strategy instruction to improve the achievement of students with and without disabilities in mainstream classes. Studies describing three types of strategy instruction as an inclusive practice have been conducted: model-lead-test strategy instruction, the Strategies Intervention Model, and the strategies integration approach.

\section{Model-Lead-Test Strategy Instruction}

Model-lead-test strategy instruction (MLT) is a three-stage instructional process for teaching students learning strategies (Idol, 1987). During the first stage, teachers model for students how to use a strategy correctly. During the second stage, teachers lead students to practice using the strategy correctly. During the third stage, teachers test students' independent use of the strategy. Once students attain a criterion percentage score of $80 \%$ correct on two consecutive tests, instruction on the strategy is terminated. Overall, the goal of using this instructional process is for teachers to gradually shape students' ability to use a learning strategy independently.

Idol (1987) examined the effects of teaching a story-mapping strategy using the MLT procedure on elementary students' reading comprehension. The study was conducted in a split third- and fourth-grade classroom, with 27 students, three of whom had learning disabilities. The students with and without disabilities were randomly assigned to one of two reading groups in which they received instruction in the strategy. The effects of the intervention were analyzed using a multiple-baseline design. Across both reading groups, implementation of the story-mapping strategy resulted in a substantial and positive shift in reading comprehension scores. Examination of the data across subjects indicated a similar pattern of improvement for students with learning disabilities. Specifically, the mean scores of the students with learning disabilities on reading comprehension tests, from baseline to maintenance, increased 40,65 , and 20 percentage points, respectively. As a result, two of the students were earning average scores of $75 \%$ or better on reading comprehension tests.

\section{The Strategies Intervention Model}

A second approach to strategy instruction is the Strategies Intervention Model (SIM) (Deshler \& Schumaker, 1988). The SIM, developed by researchers associated with the University of Kansas Center for Research on Learning, has been validated extensively in special education settings. Through the SIM, students are taught learning strategies over two phases of instruction: the acquisition phase and the generalization phase. In the acquisition phase, students learn to use the strategy effectively and efficiently. During the generalization phase, students learn to apply and adapt the strategy to new settings and circumstances. More specifically, during the acquisition phase, teachers describe the strategy, model how it is used, provide students opportunities to practice talking about and using the strategy, and give students corrective feedback on how to improve their use of the strategy. Once students have mastered the strategy, they are taught how to 
apply, modify, and use it in new settings during the generalization phase. Though designed originally to be used in resource room settings, effects of the SIM have been investigated recently in the general education classroom.

In the first study, Beals (1983) examined the effectiveness of teaching learning strategies to improve the reading skills of ninth- and tenth-grade students with and without learning disabilities in a high-school English class. Students were taught the Self-Questioning Strategy (Schumaker, Deshler, Nolan, \& Alley, 1994) and the Paraphrasing strategy (Schumaker, Denton, \& Deshler, 1984). A part-time assistant was provided to grade students' strategy practice attempts. Although instruction was provided to all the students in the class, data were collected on three students with learning disabilities, three low-achieving students, and three high-achieving students. Each of the strategies was taught over the course of a semester, and cooperative learning activities were used to assist teachers in delivering instruction. Effects of the strategy instruction interventions on each student's performance were analyzed using a multiple-baseline-across-strategies design.

Results of the study indicated that all of the students mastered the learning strategies, and their reading comprehension scores increased substantially. The average reading comprehension quiz score on grade-level material for low-achieving students rose from $30 \%$ during baseline to $70 \%$ at posttest, for high-achieving students from $76 \%$ to $98 \%$, and for students with learning disabilities from $22 \%$ to $70 \%$. Data on consumer satisfaction indicated that teachers were satisfied with the instruction associated with both of the strategies; however, they thought they did not have enough time to implement the instructional procedures as designed had they not received help of the part-time assistant. The student satisfaction ratings for the procedures associated with both strategies were in the neutral range.

More recently, Harris, Miller, and Mercer (1995) conducted a study measuring the effects of using the SIM approach to teach a strategy designed to improve students' ability to perform multiplication facts and solve multiplication word problems using a component of the Strategic Math Series (Mercer \& Miller, 1992). The strategy was taught in six second-grade general education classrooms to $112 \mathrm{stu}$ dents, 13 of whom had mild disabilities. A multiple-baseline design across classes was employed to analyze the effects of the intervention. Instruction in the strategy took place during students' regularly scheduled time for math and was implemented during the 8-week period when multiplication typically was taught in the second grade for the participating district. Results of the intervention indicated that, overall, the students with disabilities performed similarly to their nor- mally achieving peers in all phases of instruction with the exception of word problems, and both groups improved their multiplication skills substantially over the course of the study. On the baseline math facts measure given to all students, students with mild disabilities as well as students without disabilities earned an average score of $15 \%$ correct. Following instruction, students with disabilities improved their average scores to $70 \%$ correct, whereas the scores of students without disabilities increased to $85 \%$ correct.

In a third study, Wedel, Deshler, and Schumaker (1988) conducted a study examining the effects of the LINCS strategy (Ellis, 1992). This strategy was designed to improve students' understanding and recall of content-area vocabulary words. The five-step strategy was designed to guide students to mentally link a new vocabulary word and its definition with prior knowledge. During the first step, a student writes down the new word being learned (e.g., fief) and its definition (land given by king for fighting in army) on a flashcard. The student then makes a mental image of the definition. After visualizing the definition, the student writes a word (called a "reminding" word) that sounds like the new vocabulary word (e.g., chief) on the card. Next the student combines his or her visual image and reminding word in a short phrase or "story" (e.g., "The man was chief of his land") and writes it on the card. Finally, the student studies the flashcard.

Effectiveness of the strategy instruction was studied with 63 fifth- and sixth-grade students, of whom 11 had mild disabilities. A pretest, posttest comparison group design was used for the study. Students in the experimental group were taught the strategy during their English class, four to five classes per week, 20-30 minutes each class for 8 weeks. To have time to complete the whole process on a list of words, some of the students with disabilities required additional time in a resource class even though they had mastered the strategy. Results of the study indicated that, after controlling for pretest differences, students in the experimental group recalled the definitions of significantly more vocabulary words than did students in the comparison group. Specifically, students with disabilities, on average, earned a pretest score of $53 \%$ and a posttest score of $77 \%$. Students without disabilities, on average, earned a pretest score of $84 \%$ and a posttest score of $92 \%$.

\section{The Strategies Integration Approach}

Commonly, strategies instruction is separate from content instruction and, as a result, requires additional classroom instructional time. In many cases this requirement limits stu- 
dents' opportunities to learn to apply strategies to curricular content. In an effort to increase students' opportunities to learn and use strategies, Scanlon, Deshler, and Schumaker (1996), in cooperation with secondary general education teachers (Scanlon, Schumaker, \& Deshler, 1994), created the strategies integration approach. Designed to integrate instruction in a learning strategy with instruction in classroom content, the strategies integration approach consists of three phases of instruction. During the first phase, teachers introduce their students to the idea of strategic learning. During the second phase, teachers describe and model the strategy using classroom content. During the third phase, students practice using the strategy to learn classroom content.

In a study on the efficacy of the strategies integration approach (Scanlon, et al., 1996), students were taught a learning strategy called ORDER. The ORDER Strategy was designed to enable students to identify key information and depict how the information is related. Students using the strategy take notes about information, recognize the structure of the information, create a graphic organizer of the information, and use the graphic organizer for studying or writing purposes. Participating in the study were 204 sixth-, seventh-, and eighthgrade students, 17 of whom had learning disabilities. A pretest, posttest comparison-group design was used. For one semester, the experimental students' social studies teachers introduced, modeled, and had students practice the ORDER Strategy in conjunction with the content being taught for an average of 25 minutes a week. Comparison students received content instruction without instruction in the ORDER Strategy.

Results of the study revealed that experimental students with and without learning disabilities scored significantly higher than comparison students on a test measuring their use of the strategy. Moreover, the posttest scores of students with learning disabilities did not differ significantly from those of their peers without disabilities. In terms of consumer satisfaction, experimental students with and without learning disabilities alike indicated mild satisfaction with the approach. Teachers reported satisfaction with the approach and said they think teaching students how to organize content is important, but they added that the demands of covering required content prevented them from implementing the strategy instruction as often as they would have liked.

\section{Conclusions}

Strategy instruction seems to have potential as an inclusive practice. In each of the studies described above, use of strategy instruction improved the academic performance of students both with and without disabilities enrolled in general education classes. Another factor supporting the use of strategy instruction is that it was shown to be effective across many grade levels (e.g., 2nd-10th grades) and in varying skill and content area classes (e.g., math, reading, social studies, and English). Finally, in the studies reporting consumer satisfaction data (Beals et al., 1983; Scanlon et al., 1996) teachers indicated that teaching students about how to process information is important.

Despite these promising findings, several issues must be considered. In the studies reporting consumer satisfaction data (Beals, 1983; Scanlon et al., 1996), teachers expressed that the time required to deliver strategy instruction is a problem for them. In the study reported by Beals et al. (1983), teachers indicated that in order to teach strategies in their classes, they had to give up teaching some content. Likewise, in the study reported by Scanlon et al. (1996), teachers indicated they were not able to deliver strategy instruction as often as they would have liked because of other demands such as covering a certain amount of content by the end of the school year. Even when teachers are willing to make this trade-off, strategy instruction provided in general education classes may not always be enough for some students with disabilities to learn the strategy or benefit from its use. For example, in the study reported by Idol (1987), after receiving instruction on a reading comprehension strategy, one of the three students with learning disabilities still earned an average score of $55 \%$ on reading comprehension tests. In the study reported by Wedel et al. (1988) to use the LINCS Strategy once they had mastered it, students with learning disabilities required more instructional time than did the other students in the class. Still, these limitations must be considered in light of the fact that in the study by Harris et al. (1995), teachers were able to teach students the same math skills, in the same amount of instructional time used in the district historically, and obtained positive results for students with learning disabilities when they used strategy instruction.

This initial research on strategy instruction as a inclusive practice underscores the challenge inherent in finding enough time to instruct students to mastery in a given learning strategy while still covering the required curriculum within the general education classroom. This challenge did not seen to be an issue in the Harris et al. (1995) study, in which the content and the strategy were a direct match. Nevertheless, in classes where strategy instruction is an "add-on," the challenge seems particularly difficult. Additional work is needed to create the types of instructional conditions in which complex learning strategies as well as the required content can be taught and learned within the general education classroom in such a way that students and teachers are satisfied. 


\section{SUMMARY}

The purpose of this review has been to describe and critically examine studies on inclusive practices and to help clarify which, if any, can be considered validated practices that fit the realities that today's public school teachers face. This review illustrates that few validated practices exist for teachers to use. Despite the strong advocacy and emphasis for inclusive placements, surprisingly few inclusive practices were found in our search. All together, only 29 studies describing the effects of 14 different inclusive practices met the criteria established for this review. Clearly, more research and development are needed. This review, however, has illuminated some promising inclusive practices for improving the academic achievement of students with and without disabilities enrolled in general education classrooms. Each of the inclusive practices described in this review has positively impacted the academic achievement of students with and without disabilities in general education classes to some extent.

Although several promising practices have been identified, each practice has significant limitations. In some cases, the practice did not produce socially significant results for all students. For example , in several studies (e.g., Higgins et al., 1992; Jenkins et al., 1991; Slavin et al., 1984a) the inclusive practice did not affect the academic performance of students with mild disabilities positively. In other studies reporting positive effects, the interventions were not always powerful enough to help all students with mild disabilities improve academically (Phillips et al., 1993) or earn passing grades (e.g., Bulgren et al., 1988). In other cases, the time allotted for general education instruction was not sufficient to enhance the performance of students with disabilities. For example, in several studies (e.g., Lenz et al., 1987; Pomerantz et al., 1994; Wedel et al., 1988), before implementation of an inclusive practice helped some students with mild disabilities perform better academically, these students required additional instruction or practice on the intervention in a resource class. Thus, for some students with disabilities to be successful academically in general education classes, implementation of an inclusive practice alone may not be sufficient.

In still other cases, the practices may not fit the realities that general education teachers face. For example, some of the inclusive practices (e.g., Beals, 1983; Harris, et al., 1995; Hofmeister et al., 1989; Kelly et al., 1990; Slavin et al., 1984b; Wedel et al., 1988) required the standard curriculum to be altered or changed. Based on the positive effects of these practices, one might conclude that altering or changing the curricula may be an effective strategy. Nevertheless, whether teachers are willing to change or alter the standard curriculum to include students with disabilities more successfully in their classes is unknown. Although some of the inclusive practices were designed specifically to support teachers' instruction of the standard curricula (e.g., Horton et al., 1989, 1990; Maheady et al., 1988; Phillips et al., 1993; Pomerantz et al., 1994) whether teachers can and will use all of them regularly is unknown.

Effects of the inclusive practices described in this review also must be considered in light of the fact that, in many of the studies, the students with mild disabilities may not have been representative of the general population of students with mild disabilities. That is, the students with disabilities may have been enrolled in the participating general education classes because they were less affected by their disabilities than other students with mild disabilities who were receiving instruction in self-contained classrooms or who were spending a large percentage of their day in a pull-out situation. Thus, the effectiveness of the inclusive practices reviewed here for the whole population of students with mild disabilities is unknown at this time.

The difficulty inherent in creating powerful and practical practices for teacher use is underscored by the low number of inclusive practices that have been developed and studied. Nevertheless, the need for validated inclusive practices is being felt more strongly today than ever. Obviously, before the fields of special education and general education can include all students with disabilities successfully in general education classrooms, more research and development are needed. To determine if a practice is powerful and practical, researchers must conduct studies in light of the realities general education teachers face. Therefore, at a minimum, future studies on inclusive practices should:

- Report the effects a practice has on all students enrolled in a general education class

- Indicate if the effects of the practice are socially and not merely statistically significant (i.e., result in students getting grades of "C" or better in the general education classroom)

- Indicate if additional support is required outside the classroom in order for students to benefit from use of the practice

- Make clear if the students with disabilities enrolled in the class are being mainstreamed or are part of a full-inclusion program for all students with disabilities

- Describe the amount of training, planning, and implementation time required for teachers to use the practice

- Indicate clearly if the practice supports or supplants the use of standard curricula

- Report both teacher and student satisfaction data for the practice.

In sum, special and general educators can be proud of their efforts to find new ways to educate students with mild disabil- 
ities in inclusive mainstream settings. Still, until more validated inclusive practices can be developed, educators and policy makers need to consider carefully the amount of support one teacher realistically can provide to any group of students. As illustrated in this review, powerful and practical inclusive practices exist; however, these practices have limitations and alone may not be sufficient to improve the academic achievement of all students. To meet the learning needs of a significant proportion of students with mild disabilities appropriately, additional instructional support outside the general education classroom may be required. Hopefully, with the continued validation of innovative inclusive practices such as those described here, the educational needs of all students with mild disabilities, we hope, will be met someday in general education classrooms. Until this hope becomes a reality, however, the additional support that some students with mild disabilities require should continue to be made available.

\section{REFERENCES}

Baker, J. M. \& Zigmond, N. (1990). Are regular education classes equipped to accommodate students with learning disabilities? Exceptional Children, 56(6), 515-526.

Beals, V. L. (1983). The effects of large group instruction on the acquisition of specific learning strategies by learning disabled adolescents. Unpublished doctoral dissertation, University of Kansas, Lawrence.

Bulgren, J. A., Deshler, D. D., \& Schumaker, J. B. (1993). The Concept Mastery Routine. Lawrence, KS: Edge Enterprises.

Bulgren, J. A., Deshler, D. D., \& Schumaker, J. B. (1995). The Concept Comparison Routine. Lawrence: University of Kansas Center for Research on Learning.

Bulgren, J. A., Lenz, B. K., Deshler, D. D., \& Schumaker, J. B. (1995). The Concept Comparison Routine: Effectiveness of a teaching routine for examining the similarities and differences of concepts to enhance the performance of secondary level students. Lawrence: University of Kansas Center for Research on Learning.

Bulgren, J. A., Lenz, B. K., Schumaker, J. B., \& Deshler, D. D. (1995). The use and effectiveness of a concept comparison routine in secondary-level mainstream classes. Lawrence: University of Kansas Center for Research on Learning.

Bulgren, J. A., Schumaker, J. B., \& Deshler, D. D. (1988). Effectiveness of a concept teaching routine in enhancing the performance of LD students in secondary-level mainstream classes. Learning Disability Quarterly, 11, 3-17.

Bulgren, J. A,. Schumaker, J. B., \& Deshler, D. D. (1994a). The Concept Anchoring Routine. Lawrence, KS: Edge Enterprises.

Bulgren, J. A., Schumaker, J. B., \& Deshler, D. D. (1994b). The use and effectiveness of a concept anchoring routine in secondary- level mainstream classes. Lawrence: University of Kansas Research on Learning.

Bulgren, J. A., Schumaker, J. B., \& Deshler, D. D. (1994c). The effects of a recall enhancement routine on the test performance of secondary students with and without learning disabilities. Learning Disabilities Research \& Practice, 9 (1), 2-11.

Bulgren, J. A., Schumaker, J. B., \& Deshler, D. D. (1995). Development and use of concept comparison devices and teaching routines by teachers in secondary-level mainstream classes. Lawrence: University of Kansas Center for Research on Learning.

Carnine, D. (1991). Curricular interventions for teaching higher order thinking to all students: Introduction to the special series. Journal of Learning Disabilities, 24(5), 261-269.

Carnine, D. (1994). The BIG Accommodations Program. Educational Leadership, 51, 87-88.

Carnine, D., Crawford, D., Harniss, M., \& Hollenbeck, K. (1995). Understanding U. S. History (Vol. 1). Eugene, OR: Considerate Publishing.

Carnine, D., \& Kameenui, E. (1992). Higher order thinking: Designing curriculum for mainstreamed students. Austin, TX: Pro-Ed.

Cawley, J. F. (1994). Science for students with disabilities. Remedial \& Special Education, 15(2), 67-71.

Damon, W., \& Phelps, E. (1989). Critical distinctions among three approaches to peer education. International Journal of Educational Research, 13, 9-20.

Delquadri, J. C., Greenwood, C. R., Stretton, K., \& Hall R. V. (1983). The peer tutoring spelling game: A classroom procedure for increasing opportunity to respond and spelling performance. Education \& Treatment of Children, 6(3), 225-239.

Delquadri, J. C., Greenwood, C. R., Whorton, D., Carta, J. J., \& Hall, R. V. (1986). Classwide peer tutoring. Exceptional Children, 52(6), 535-542.

Deshler, D. D., \& Lenz, B. K. (1989). The strategies instructional approach. International Journal of Disability, Development, \& Education, 36(3), 203-224.

Deshler, D. D., \& Schumaker, J. B. (1988). An instructional model for teaching students how to learn. In J. E. Zins \& M. J. Curtis (Eds.), Alternative educational delivery systems: Enhancing instructional options for all students (pp. 391-411). Washington, DC: National Association of School Psychologists.

Deshler, D. D., \& Schumaker, J. B. (1993). Strategy mastery by atrisk students: Not a simple matter. Elementary School Journal, 94(2), 153-167.

Ellis, E. (1992). LINCS: A starter strategy for vocabulary learning. Lawrence, KS: Edge Enterprises.

Engelmann, S., \& Carnine, D. (1982). Theory of instruction: Principles and applications. New York: Brington.

Fisher, J. B., Knight, J., \& Lenz, B. K. (1996). Pedagogies for diversity in secondary schools: Enhancing content learning. Learning Consultant Journal, 53, 6-9.

Greenwood, C. R., Delquadri, J., \& Hall, R. V. (1984). Opportunity to respond and student academic performance. In W. L. Heward, T. E. Heron, J. Trap-Porter, \& D. S. Hill (Eds.), Focus 
on behavior analysis in education (pp. 58-88). Columbus, $\mathrm{OH}$ : Charles Merrill.

Greenwood, C. R., Maheady, L., \& Carta, J. J. (1991). Peer tutoring programs in the regular education classroom. In G. Stoner, M. R. Shinn, \& H. M. Walker (Eds.), Interventions for achievement and behavior problems (pp. 179-200). Washington, DC: National Association of School Psychologists.

Harris, C. A., Miller, S. P., \& Mercer, C. D. (1995). Teaching initial multiplication skill to students with disabilities in general education classrooms. Learning Disabilities Research \& Practice, 10(3), 180-195.

Higgins, K., \& Boone, R. (1992). Hypermedia computer study guides for social studies: Adapting a Canadian history text. Social Education, 56(3), 154-159.

Hofmeister, A. M., Engelmann, S., \& Carnine, D. (1989). Developing and validating science education videodiscs. Journal of Research in Science Teaching, 26(8), 665-667.

Horton, S. V., \& Lovitt, T. C. (1989). Using study guides with three classifications of secondary students. Journal of Special Education, 22(4), 447-462.

Horton, S. V., Lovitt, T. C., \& Bergerud, D. (1990). The effectiveness of graphic organizers for three classifications of secondary students in content area classes. Journal of Learning Disabilities, 23(1), 12-22.

Horton, S. V., Lovitt, T. C., Givens, A., \& Nelson, R. (1989). Teaching social studies to high school students with academic handicaps in a mainstream setting: Effects of a computerized study guide. Journal of Learning Disabilities, 22(2), 102-107.

Horton, S. V., Lovitt T. C., \& Slocum, T. (1988). Teaching geography to high school students with academic deficits: Effects of a computerized map tutorial. Learning Disability Quarterly, 11, 371-379.

Idol, L. (1987). Group story mapping: A comprehensive strategy for both skilled and unskilled readers. Journal of Learning Disabilities, 20(4), 196-205.

Jenkins, J. R., \& Jenkins, L. M. (1985). Peer tutoring in elementary and secondary programs. Focus on Exceptional Children, $17(6), 1-12$.

Jenkins, J. R., Jewell, M., Leicester, N, Jenkins, L., \& Troutner, N. M. (1991). Development of a school building model for educating students with handicaps and at-risk students in general education classrooms. Journal of Learning Disabilities, 24, 311-320.

Joint Committee on Teachers Planning for Students with Disabilities. (1995). Planning for academic diversity in America's classrooms: Windows on reality, research, change, and practice. Lawrence: The University of Kansas Center for Research on Learning.

Kauffman, J. M. (1994). Places of change: Special education's power and identity in an era of educational reform. Journal of Learning Disabilities, 27(10), 610-618.

Kelly, B., Gersten, R., \& Carnine, D. (1990). Student error patterns as a function of curriculum design: Teaching fractions to reme- dial high school students and high school students with learning disabilities. Journal of Learning Disabilities, 23(1), 23-29.

Lenz, B. K., Alley, G. R., \& Schumaker, J. B. (1987). Activating the inactive learner: Advanced organizers in the secondary content classroom. Learning Disability Quarterly, 10, 53-66.

Lenz, B. K., Bulgren, J. A., \& Hudson, P. (1990). Content enhancement: A model for promoting the acquisition of content by individuals with learning disabilities. In T. E. Scruggs \& B. L. Y. Wong (Eds.), Intervention research in learning disabilities (pp. 122-165). New York: Springer-Verlag.

Lenz, B. K., Bulgren, J. A., Schumaker, J. B., Deshler, D. D., \& Boudah, D. A. (1994). The Unit Organizer Routine. Lawrence, KS: Edge Enterprises.

Lenz, B. K., Marrs, R. W., Schumaker, J. B., \& Deshler, D. D. (1993). The Lesson Organizer Routine. Lawrence, KS: Edge Enterprises.

Lenz, B. K., Schumaker, J. B., Deshler, D. D., Boudah, D. J., Vance, M., Kissam, B., Bulgren, J. A., \& Roth, J. (1993). The unit planning routine: A guide for inclusive unit planning (Research Report). Lawrence: University of Kansas Center for Research on Learning.

Lovitt, T. C., \& Horton, S. V. (1988). How to develop study guides. Journal of Reading, Writing, and Learning Disabilities, 2 , 213-221.

Lovitt, T. C., \& Horton, S. V. (1991). Adapting textbooks for mildly handicapped adolescents. In G. Stoner, M. R. Shinn, \& H. M. Walker (Eds.), Interventions for achievement and behavior problems (pp. 439-472). Washington, DC: National Association of School Psychologists.

Maheady, L., Sacca, M. K., \& Harper, G. F. (1987). Classwide Student Tutoring Teams: The effects of peer-mediated instruction of the academic performance of secondary mainstreamed students. Journal of Special Education, 21(3), 107-121.

Maheady, L., Sacca, M. K., \& Harper, G. F. (1988). Classwide peer tutoring with mildly handicapped high school students. Exceptional Children, 55(1), 52-59.

Mandoli, M., Mandoli, P., \& McLaughlin, T. F. (1982). Effects of same-age peer tutoring on the spelling performance of a mainstreamed elementary LD student. Learning Disability Quarterly, 5, 185-189.

McIntosh, R., Vaughn, S., Schumm, J. S., Haager, D., \& Lee, O. (1993). Observations of students with learning disabilities in general education classrooms. Exceptional Children, 60(3), 249-261.

Mercer, C. \& Miller, S. P. (1992). Multiplication facts 0 to 81. Lawrence, KS: Edge Enterprises.

Palincsar, A. S., David, Y. M., Winn, J. A., \& Stevens, D. (1991). Examining the contexts of strategy instruction. Remedial \& Special Education, 12(3), 43-53.

Phillips, N. B., Hamlett, C. L., Fuchs, L. S., \& Fuchs D. (1993). Combining classwide curriculum-based measurement and peer tutoring to help general educators provide adaptive education. Learning Disabilities Research \& Practice, 8(3), 148-156. 
Pomerantz, D. J., Windell, I. J., \& Smith, M. A. (1994). The effects of classwide peer tutoring and accommodations on the acquisition of content area knowledge by elementary students with learning disabilities. LD Forum, 19(2), 28-32.

Pressley, M., Burkell, J., Cariglia-Bull, T., Lysynchuk, L., McGoldrick, J. A., Schneider, B., Snyder, B. L., Symons, S., \& Woloshyn, V. E. (1990). Cognitive strategy instruction that really improves children's academic performance. Cambridge, MA: Brookline Brooks.

Scanlon, D., Deshler, D. D., \& Schumaker, J. B. (1996). A strategy for students in inclusive classrooms to organize and represent content. Learning Disabilities Research \& Practice, 11, 41-57.

Scanlon, D., Schumaker, J. B., \& Deshler, D. D. (1994). Collaborative dialogues between teachers and researchers to create educational interventions: A case study. Journal of Educational \& Psychological Consultation, 5(1), 69-76.

Schumaker, J. B., Denton, P. H., \& Deshler, D. D. (1984). The Paraphrasing Strategy. Lawrence, KS: Edge Enterprises.

Schumaker, J. B., Deshler, D. D., \& McKnight, P. C. (1991). Teaching routines for areas at the secondary level. In G. Stoner, M. R. Shinn, \& H. M. Walker (Eds.), Interventions for achievement and behavior problems (pp. 473-494). Washington, DC: National Association of School Psychologists.

Schumaker, J. B., Deshler, D. D., Nolan, S. M., \& Alley, G. R. (1994). The Self-Questioning Strategy. Lawrence, KS: Edge Enterprises.

Slavin, R. E., Madden, N. A., \& Leavey, M. (1984a). Effects of cooperative learning and individualized instruction on mainstreamed students. Exceptional Children, 50(5), 434-443.
Slavin, R. E., Madden, N. A., \& Leavey, M. (1984b). Effects of team assisted individualization on the mathematics achievement of academically handicapped and nonhandicapped students. Journal of Educational Psychology, 76(5), 813-819.

Slavin, R. E., Stevens R. J., \& Madden, N. A. (1988). Accommodating student diversity in reading and writing instruction: A cooperative learning approach. Remedial \& Special Education, 9(1), 60-66.

Top, B. L., \& Osguthorpe, R. T. (1987). Reverse-role tutoring: The effects of handicapped students tutoring regular class students. Elementary School Journal, 87(4), 413-423.

Wedel, M., Deshler, D. D., \& Schumaker, J. B. (1988). Effects of instruction of a vocabulary strategy in a mainstream class. Unpublished masters thesis, University of Kansas, Lawrence.

Zigmond, N., Jenkins, J., Fuchs, L., Deno, S., Fuchs, D., Baker, J. N., Jenkins, L., \& Couthino, M. (1995). Special education in restructured schools: Findings from three multi-year studies. Phi Delta Kappan, 76, 531-540.

This review was supported in part by Grant \# H029D20023 from the U. S. Department of Education, Office of Special Education to the University of Kansas. Statements do not reflect the position or policy of this agency, and no official endorsement by then should be inferred.

We would like to thank Barbara Glaeser, Sharrel Houx, Jim Knight, Kirsten McBride, Paula Mehochko, David Scanlon, Linda Seybert, and Lisa Walsh for their help in preparing this manuscript. 